\title{
Characterization of Carbon Nanotubes-Gold Nanoparticles Composite Film Modified Electrode and Voltammetric Determination of Mefenamic Acid
}

\author{
Jingjing Yu, Jiangwen Li, Faqiong Zhao and Baizhao Zeng* \\ Department of Chemistry, Wuhan University, Wuhan 430072, P.R. China
}

\begin{abstract}
Um novo eletrodo modificado com nanotubos de carbono foi fabricado, com base em nanotubos de carbono multi-paredes (MWCNTs) dispersos em colóide de nanopartículas de ouro (AuNPs). Foi observado que MWCNTs foram dispersos no colóide AuNPs homogeneamente. Fosfato ácido de dihexadecil (DHP) foi adicionado à suspensão para preparar um filme mais estável. $\mathrm{O}$ filme mostrou estrutura em rede e teve boa função de transferência de elétron. O comportamento eletroquímico do ácido mefenâmico, no eletrodo coberto com filme composto, mostrou um pico anódico irreversível, o qual foi muito maior do que para o eletrodo de carbono vítreo (GCE), devido ao co-efeito de MWCNTs e AuNPs na oxidação eletroquímica do ácido mefenâmico. Sob ótimas condições, a corrente do pico anódico foi linear à concentração do ácido mefenâmico, no intervalo de $1,0 \times 10^{-7}$ a $2,0 \times 10^{-5} \mathrm{~mol} \mathrm{~L}^{-1}$. O limite de detecção foi estimado em $1,0 \times 10^{-8} \mathrm{~mol} \mathrm{~L}^{-1}$ após $120 \mathrm{~s}$ de pré-concentração. O método foi aplicado com sucesso à determinação do ácido mefenâmico em amostra medicinal.
\end{abstract}

A novel carbon nanotubes modified electrode was fabricated, which was based on multi-walled carbon nanotubes (MWCNTs) dispersed in gold nanoparticles (AuNPs) colloid. It was observed that MWCNTs were dispersed in AuNPs colloid homogenously. Dihexadecyl hydrogen phosphate (DHP) was added into the suspension to prepare a more stable film modified electrode. The film showed net structure and had good electron-transfer function. On the composite film coated electrode, the electrochemical behavior of mefenamic acid was studied and an irreversible anodic peak was obtained, which was much larger than that on a bare glassy carbon electrode (GCE), due to the co-effect of MWCNTs and AuNPs on the electrochemical oxidation of mefenamic acid. Under the optimized conditions the anodic peak current was linear to the concentration of mefenamic acid in the range of $1.0 \times 10^{-7}$ to $2.0 \times 10^{-5} \mathrm{~mol} \mathrm{~L}^{-1}$. The detection limit was estimated to be $1.0 \times 10^{-8} \mathrm{~mol} \mathrm{~L}^{-1}$ after $120 \mathrm{~s}$ preconcentration. The method was applied successfully to the determination of mefenamic acid in medicine sample.

Keywords: mefenamic acid, carbon nanotubes, gold nanoparticles, dihexadecyl hydrogen phosphate, modified electrode

\section{Introduction}

Mefenamic acid (i.e. $\mathrm{N}-(2,3$-Xylyl) anthranilic acid, MA) is a non-steroidal drug with anti-inflammatory, analgesic and anti-pyretic activity. ${ }^{1-9}$ Thus it is widely used in treating musculoskeletal and joint disorders such as osteoarthritis and rheumatoid arthritis. Several methods have been developed for MA determination, including spectrophotometry, ${ }^{1,2}$ fluorimetry, ${ }^{3-5}$ liquid chromatography (LC), ${ }^{6}$ and chemiluminescence (CL), ${ }^{7}$ etc. However, these methods are generally complicated and time-consuming

*e-mail: bzzeng@whu.edu.cn because extraction ${ }^{6}$ or derivation procedure ${ }^{1,5,7}$ is usually required.Electroanalytical methods are usually more simple and sensitive, thus the attempt to determine MA electrochemically is of some significance. Liu and Song ${ }^{10}$ developed a lanthanum hydroxide nanowires modified carbon paste electrode for the voltammetric determination of MA. The linear range was $2.0 \times 10^{-11}$ to $4.0 \times 10^{-9} \mathrm{~mol} \mathrm{~L}^{-1}$ and the detection limit was $6.0 \times 10^{-12} \mathrm{~mol} \mathrm{~L}^{-1}$. Santini et al. ${ }^{11}$ prepared a potentiometric ion sensor for the determination of MA in pharmaceuticals and human blood serum. The sensor showed linear response to MA over the range of $1.0 \times 10^{-6}$ to $1.0 \times 10^{-2} \mathrm{~mol} \mathrm{~L}^{-1}$; the detection limit was $6.2 \times 10^{-7} \mathrm{~mol} \mathrm{~L}^{-1}$. 
Carbon nanotubes (CNTs), consisting of cylindrical graphite sheets with nanometer diameter, combine in a unique way with large surface area, high electrical conductivity and remarkable mechanical properties. ${ }^{12} \mathrm{CNTs}$ are widely used to prepare modified electrodes and construct sensing films as they can enhance electron transfer rate and sensitivity. ${ }^{13-16}$ When they are utilized for those purposes, they are generally dispersed in N,N-dimethylformamide ${ }^{17-19}$ and then cast on the surface of substrate electrodes. But the dispersion of CNTs in solvents is usually unsatisfactory due to their insolubility, and the resulting suspension is unstable. In order to improve the dispersion of CNTs in solvents and the characteristic of the resulting electrodes, some methods were attempted. For example, Wu and co-workers ${ }^{20,21}$ prepared CNTs coated electrodes by using a suspension containing acid-treated CNTs and dihexadecyl hydrogen phosphate (DHP). They declared that the suspension was quite stable. The resulting electrodes were applied to the detection of some biomolecules and heavy metal ions with satisfying results. Wang et al ${ }^{22}$ improved the dispersion of CNTs by introducing Nafion and then fabricated a glucose biosensor based on the Nafion - solubilized CNTs. Gorski and co-workers developed a CNTs and chitosan composite film for preparing dehydrogenase biosensors. ${ }^{23}$ Through adopting such methods the application scope of CNTs modified electrodes was widened greatly.

Herein, multi - walled carbon nanotubes (MWCNTs) were dispersed in a gold nanoparticles (AuNPs) colloid to prepare MWCNTs - AuNPs - DHP film coated glassy carbon electrode (GCE). The modified electrode was used to study the electrochemical behavior of MA, and it exhibited distinct enhancement effect on the electrochemical response of MA.

\section{Experimental}

\section{Reagents and apparatus}

MA (Purity: $99 \%$, Zhejiang Tianxin Pharmaceutical Co., China.) stock solution $\left(1.0 \times 10^{-3} \mathrm{~mol} \mathrm{~L}^{-1}\right)$ was prepared with ethanol and kept at $4{ }^{\circ} \mathrm{C}$. MA capsules came from Shanxi Yishengtang Pharmaceutical Co. (Shanxi, China). Before determination, a capsule (labeled amount: $0.25 \mathrm{~g}$ per capsule) was ground into powder, dissolved in $100 \mathrm{~mL}$ ethanol and filtered. The filtered solution was determined. DHP (from Fluka, USA) was stored at $-18^{\circ} \mathrm{C}$. MWCNTs (Chengdu Organic Chemicals Co., Ltd., China) were refluxed for $16 \mathrm{~h}$ in $\mathrm{HNO}_{3}$ before use. Other chemicals used were of analytical grade and water was redistilled.

All voltammetric experiments were performed on a CHI 660A electrochemical analyzer (Chenhua Instru. Co.,
Shanghai, China). The working electrode was a modified GCE with a geometric area of $0.033 \mathrm{~cm}^{2}$. A saturated calomel electrode (SCE) served as reference electrode, and a Pt wire as counter electrode. The electrochemical impedance spectroscopy (EIS) was recorded with an EG \& G Model 273 electrochemical workstation and EG \& G Model 5210 lock-in amplifier (PAR, USA) powered by Echem Software. In EIS, the frequency range was from $100 \mathrm{mHz}$ to $100 \mathrm{kHz}$ with the amplitude of $5 \mathrm{mV}$, and the dc potential was the average potential ( $v s$. SCE) of the oxidation and the reduction peaks. The scanning electron microscopy (SEM) images were obtained using a Quanta 200 SEM (FEI Co., Holand). Before recording SEM images, a drop of MWCNTs-AuNPsDHP suspension was transferred onto a glassy carbon plate, and allowed it to dry in air at room temperature. Ultraviolet visible (UV-Vis) absorption spectrometry was performed with a TU-1901 spectrophotometer (Purkinje General Instrument Co. Ltd., Beijing, China).

\section{Preparation of AuNPs colloid}

Citrate-capped AuNPs were prepared as described in the literatures. ${ }^{24,25}$ In brief, $10 \mathrm{~mL}$ of $0.4 \mathrm{mg} \mathrm{mL}^{-1} \mathrm{HAuCl}_{4}$ aqueous solution was heated to boiling, and then $1 \mathrm{~mL}$ of $1 \%$ sodium citrate aqueous solution was introduced. The mixture was maintained at $100{ }^{\circ} \mathrm{C}$ until the solution color turned to wine red. The mixture was filtered with a micro-pore filter, and the solution (i.e. AuNPs colloid) was collected.

\section{Preparation of MWCNTs-AuNPs-DHP composite film modified electrode}

A $3 \mathrm{mg}$ MWCNTs was mixed with $1.5 \mathrm{~mL}$ AuNPs colloid with the aid of ultrasonic agitation, thus a black suspension of MWCNTs was obtained. Then 1.5 $\mathrm{mL}$ of $1 \mathrm{mg} \mathrm{mL}^{-1} \mathrm{DHP}$ suspension was added into the black suspension, followed by ultrasonic agitation. The resulting suspension was noted as MWCNTs-AuNPsDHP. Before modification, the GCE was polished to a mirror smooth with $0.05 \mu \mathrm{m} \mathrm{Al}_{2} \mathrm{O}_{3}$ slurry, rinsed with water, then ultra-sonicated in water and ethanol for several minutes. After that, $6 \mu \mathrm{L}$ of the MWCNTsAuNPs-DHP suspension was transferred onto the GCE surface, and the solvent was evaporated under room temperature. Thus MWCNTs-AuNPs-DHP/GCE was obtained. For comparison, AuNPs film coated GCE (AuNPs/GCE), DHP film coated GCE (DHP/GCE), MWCNTs-AuNPs film coated GCE (MWCNTs-AuNPs/ GCE) and MWCNTs-DHP film coated GCE (MWCNTsDHP/GCE) were prepared by using similar method. 


\section{Experimental procedure}

$10 \mathrm{~mL} 0.1 \mathrm{~mol} \mathrm{~L}^{-1}$ phosphate buffer solution (PBS, $\mathrm{pH}$ 6.47) with certain amount of MA was transferred to a single-compartment cell, then the three-electrode system was immersed into it. After preconcentration on open circuit for $120 \mathrm{~s}$, the stirrer was turned off, and followed by $10 \mathrm{~s}$ rest. Then potential scan was initiated and voltammograms were recorded between 0.2 to $0.9 \mathrm{~V}$ at scan rate of $50 \mathrm{mV} \mathrm{s}^{-1}$. After each measurement, the modified electrode underwent successive cyclic potential scan in the blank solution to refresh for reuse.

\section{Results and Discussion}

\section{Feature of MWCNTs-AuNPs-DHP suspension}

When MWCNTs were dispersed in AuNPs colloid with the aid of ultrasonic agitation, a black and homogenous suspension could be obtained. It was quite stable; no precipitate was observed after storing at $4{ }^{\circ} \mathrm{C}$ for two months. This should be ascribed to the electrostatic repulsion between the citrate-capped AuNPs and the oxidized carbon nanotubes with carboxylic, carbonyl and hydroxyl groups, which made the big bundles of MWCNTs dispersed. However, MWCNTs-AuNPs film was unstable in aqueous solution due to the dissolvability of AuNPs. To solve the problem, DHP was introduced. DHP is a hydrophobic surfactant containing two long alkyl chains and it can form a uniform and stable film. Figure 1 shows the SEM image of MWCNTs-AuNPs-DHP composite film. AuNPs (i.e. the small bright dots) are dispersed on the surface of MWCNTs, their diameters are 20-40 nm. They are immobilized on the electrode surface with the aid of mushy DHP film. The composite film shows net structure, which may be favorable for electron transfer.

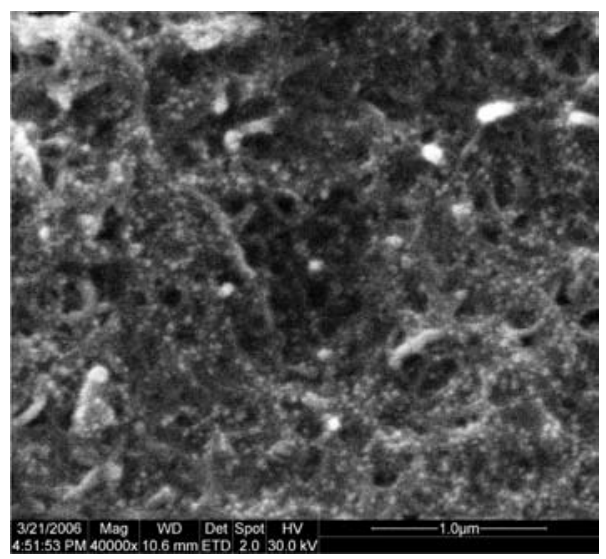

Figure 1. SEM image of MWCNTs-AuNPs-DHP composite film on glassy carbon surface.

\section{EIS of the film modified electrode}

Figure 2 shows the EIS of various electrodes in $5 \times 10^{-3}$ mol L-1 $\mathrm{Fe}(\mathrm{CN})_{6}^{3-14-}$ solution. The Nyquist plot of DHP/GCE is a semicircle with large diameter in full frequency range, indicating that DHP film causes great electron transfer resistance. The Nyquist plots of AuNPs/GCE and bare GCE are a small semicircle plus a straight line. But for AuNPs/ GCE the semicircle is smaller, meaning that the AuNPs film could reduce the electron transfer resistance to some extent. For MWCNTs-AuNPs-DHP/GCE, MWCNTs-AuNPs/ GCE and MWCNTs-DHP/GCE, a straight line appears in high frequency range, indicating that the electron transfer resistance decreases significantly. No significant difference is observed among them, which implies that the decrease of electron transfer resistance is mainly due to the increase of effective electrode surface and the promotion effect of MWCNTs on electron transfer.

Voltammetric response of MWCNTs-AuNPs-DHP/GCE to $M A$

Figure 3 displays the cyclic voltammograms (CVs) of the MWCNTs-AuNPs-DHP/GCE in given solution. It can be seen that the buffer solution does not exhibit any voltammetric peaks in the potential range. Without preconcentration, MA just causes a small anodic peak, corresponding to the oxidation of MA. After $120 \mathrm{~s}$ preconcentration on open-circuit, the anodic peak current increases markedly and the peak potential shifts negatively to $0.60 \mathrm{~V}$, suggesting that MA could adsorb on the electrode surface. However, the peak current decreases rapidly when the potential scan is repeated successively, meaning that the adsorbed MA can be easily removed. In addition, a small cathodic peak is observed at around $0.58 \mathrm{~V}$ for both blank and MA solutions, which should be ascribed to the reduction of gold oxide. Therefore, the electrochemical process of MA is totally irreversible.

The linear sweep voltammograms (LSVs) of MA at different electrodes are compared (Figure 4). The anodic peak of MA is rather small on the bare GCE, DHP/GCE and AuNPs/GCE. However, on the MWCNTs-AuNPs-DHP/ GCE, the peak is enhanced remarkably, which is about 30 times as large as that on the bare GCE. Meanwhile, the peak potential shifts negatively for about $30 \mathrm{mV}$, indicating that the composite film could facilitate the electrochemical reaction. As for MWCNTs-AuNPs/GCE and MWCNTsDHP/GCE, the peak currents are about 39 times and 17 times as large as that on the bare GCE, respectively. Obviously, the increase of peak current results from the coeffect of MWCNTs and AuNPs, and DHP is not in favor of 

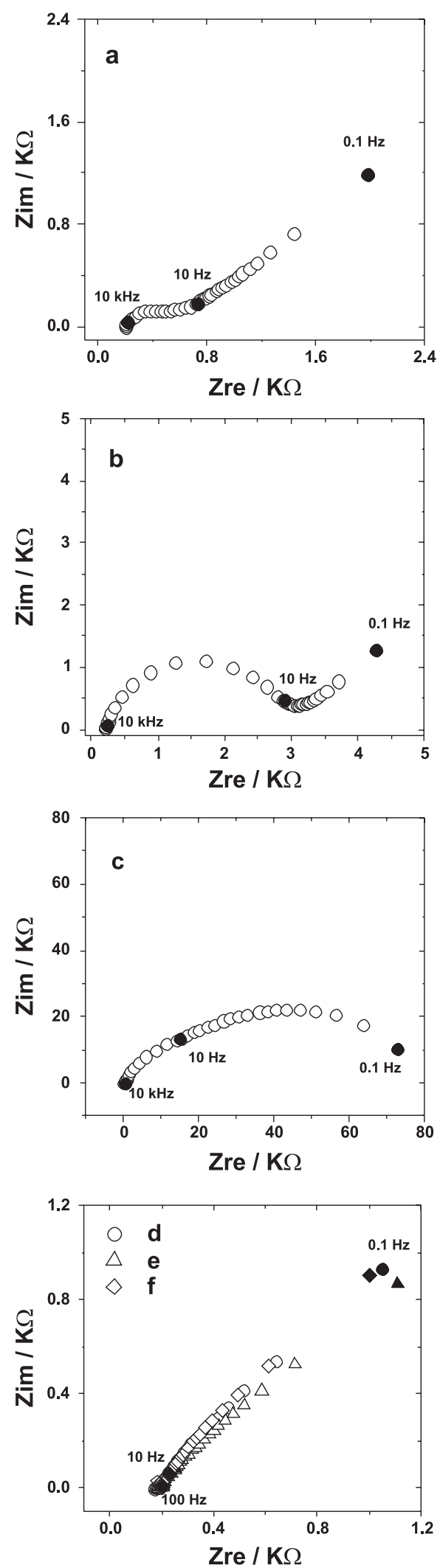

Figure 2. EIS of different electrodes. Solution composition: $0.1 \mathrm{~mol} \mathrm{~L}^{-1}$ pH 7.0 PBS plus $5 \times 10^{-3} \mathrm{~mol} \mathrm{~L}^{-1} \mathrm{Fe}(\mathrm{CN})_{6}^{3-1 / 4}$ and $1 \times 10^{-3} \mathrm{~mol} \mathrm{~L}^{-1} \mathrm{KCl}$; electrodes: AuNPs/GCE (a), bare GCE (b), DHP/GCE (c), MWCNTsDHP/GCE (d), MWCNTs-AuNPs-DHP/GCE (e) and MWCNTs-AuNPs/ GCE (f).

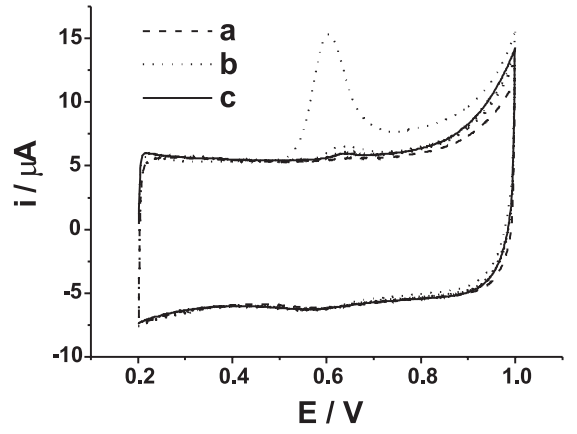

Figure 3. CVs of MWCNTs-AuNPs-DHP/GCE in $\mathrm{pH}$ 6.47 PBS containing 0 (a) and $1.0 \times 10^{-5} \mathrm{~mol} \mathrm{~L}^{-1}(\mathrm{~b}, \mathrm{c}) \mathrm{MA}$. Preconcentration time: $120 \mathrm{~s}(\mathrm{a}$, b), $0 \mathrm{~s}$ (c); curve b shows two successive cycles; scan rate: $50 \mathrm{mV} \mathrm{s}^{-1}$.

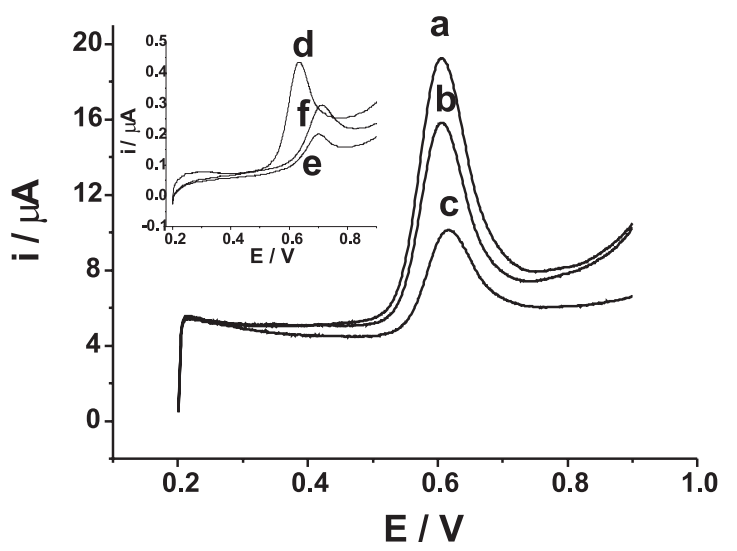

Figure 4. LSVs of $1.0 \times 10^{-5} \mathrm{~mol} \mathrm{~L}^{-1} \mathrm{MA}$ on different electrodes after $120 \mathrm{~s}$ preconcentration. Electrodes: MWCNTs-AuNPs/GCE (a), MWCNTsAuNPs-DHP/GCE (b), MWCNTs-DHP/GCE (c), bare GCE (d), DHP/ GCE (e) and AuNPs/GCE (f).

the electrochemical reaction of MA. Although the peak of MA on the MWCNTs-AuNPs/GCE is more sensitive than those on other electrodes, the MWCNTs-AuNPs-DHP/ GCE is chosen in this work as it is more stable.

\section{Effect of scan rate and solution $\mathrm{pH}$}

Figure 5 shows the effect of scan rate on the anodic peak current of MA on the MWCNTs-AuNPs-DHP/GCE. The peak current $\left(i_{p}\right)$ changes linearly with scan rate $(v)$ in the range studied $\left(10-300 \mathrm{mV} \mathrm{s}^{-1}\right)$, indicating that the electrochemical process of MA is controlled by adsorption. Additionally, the peak potential $\left(\mathrm{E}_{\mathrm{p}}\right)$ shifts in positive direction with the increase of scan rate, and there is a linear relationship between $E_{p}$ and $\ln v$. For a totally irreversible electrode process controlled by adsorption, the anodic peak potential and scan rate should obey following equation: ${ }^{26}$

$\mathrm{E}_{\mathrm{p}}=\mathrm{E}^{0^{\prime}}+\left(\mathrm{RT} / \alpha_{\mathrm{a}} \mathrm{F}\right) \ln \left(\mathrm{RTk}^{0} / \alpha_{\mathrm{a}} \mathrm{F}\right)+\left(\mathrm{RT} / \alpha_{\mathrm{a}} \mathrm{F}\right) \ln \nu$ 


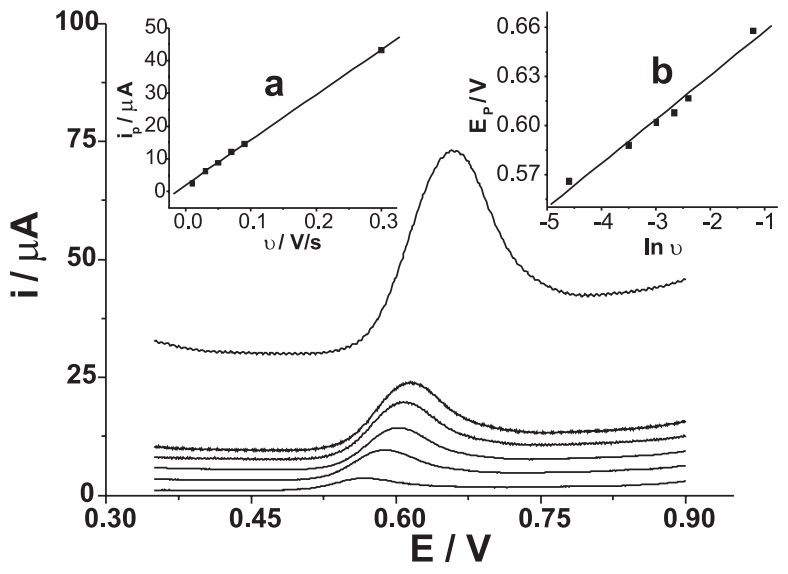

Figure 5. Effect of scan rate on LSVs of MA at MWCNTs-AuNPsDHP/GCE. Scan rate: $10,30,50,70,90,300 \mathrm{mV} \mathrm{s}^{-1}$ (from bottom to upper); insets show the plots of $\mathrm{i}_{\mathrm{p}} v s v$ and $\mathrm{E}_{\mathrm{p}} v s \ln v$; other conditions as in Figure 4.

Where $\mathrm{E}^{0^{\prime}}$ is formal potential, $\alpha$ is the electron transfer coefficient and $n_{a}$ is the number of transfer-electron in the ratedetermining step, and $\mathrm{k}^{0}$ is the electrochemical rate constant. The slope of $E_{p}-\ln v$ plot indicates that the value of $\alpha n_{a}$ is 0.96. For an irreversible electrode process, the reasonable $\alpha$ value is 0.5 . Then the number of the transfer-electron in the electrochemical oxidation can be estimated to be 2 .

The influences of $\mathrm{pH}$ on the peak current and peak potential of MA are shown in Figure 6. With increasing $\mathrm{pH}$, the peak current increases and reaches the maximum at about $\mathrm{pH}$ 6.47, then decreases quickly. At the same time, the peak shape becomes more symmetrical at $\mathrm{pH}$ 6.47. Hence PBS with pH 6.47 is chosen as the supporting electrolyte. In addition, the effect of $\mathrm{pH}$ is related to the

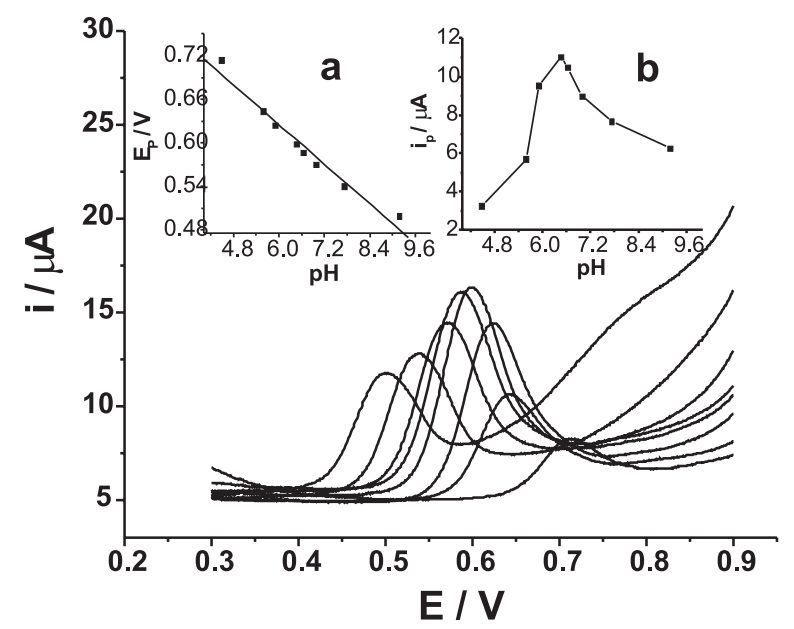

Figure 6. Effect of solution pH on LSVs of MA at MWCNTs-AuNPsDHP/GCE. Solution pH: 4.49, 5.59, 5.91, 6.47, 6.64, 6.98, 7.73, 9.18 (from left to right); insets show the plots of $\mathrm{i}_{\mathrm{p}} v \mathrm{~s} \mathrm{pH}$ and $\mathrm{E}_{\mathrm{p}} v s \mathrm{pH}$; other conditions as in Figure 4. electrochemical reaction, since proton transfer is involved in it. When solution $\mathrm{pH}$ changes from 4.49 to 9.18 the peak shifts negatively. Furthermore, the peak potential $\left(\mathrm{E}_{\mathrm{p}}\right)$ and solution $\mathrm{pH}$ show a linear relationship (Figure 6), and the regression equation is $\mathrm{E}_{\mathrm{p}}=0.898-0.046 \mathrm{pH}(\mathrm{R}=0.982)$. The slope of $0.046 \mathrm{~V} / \mathrm{pH}$ indicates that the numbers of proton and electron transferred equal..$^{27,28}$ As to the deviation of the slope from the standard value $(0.059 \mathrm{~V} / \mathrm{pH})$, it may be related to the protonation of MA. Therefore, the electrochemical oxidation of MA on MWCNTs-AuNPsDHP/GCE is expected to follow a mechanism involving the transfer of two electrons and two protons, which can be expressed as Scheme 1.

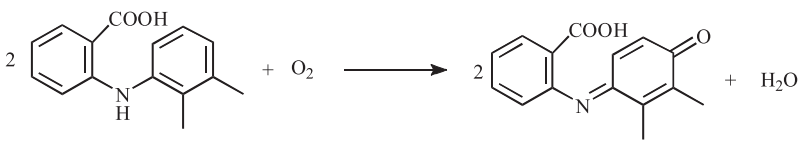

Scheme 1. Electrochemical oxidation mechanism of MA.

\section{Influence of preconcentration potential and time}

The influence of preconcentration potential on the peak current was investigated by LSV. The peak current varied slightly when the preconcentration potential changed from -0.8 to $0.5 \mathrm{~V}$. It is to say, the preconcentration of MA on the electrode surface was almost independent of electrostatic attraction. Accordingly, a preconcentration was performed under open circuit. However, the preconcentration time influenced the peak current significantly. The peak current of $1.0 \times 10^{-5} \mathrm{~mol} \mathrm{~L}^{-1} \mathrm{MA}$ increased rapidly within first $90 \mathrm{~s}$ and then grew slowly. This corresponds with the characteristic of an adsorption-controlled system. A $120 \mathrm{~s}$ preconcentration was adopted in this work.

\section{Calibration curve, reproducibility and interference}

Under the selected conditions, the peak current increased with the increase of the concentration of MA and the calibration curve was worked out (Figure 7). The peak current was linear to MA concentration in the range of $1.0 \times 10^{-7}$ to $2.0 \times 10^{-5} \mathrm{~mol} \mathrm{~L}^{-1}$, and the linear regression equation was $\mathrm{i}_{\mathrm{p}}(\mu \mathrm{A})=1.716 \mathrm{c}\left(\mu \mathrm{mol} \mathrm{L} \mathrm{L}^{-1}\right)+0.834(\mathrm{R}=0.997)$. The detection limit was $1.0 \times 10^{-8} \mathrm{~mol} \mathrm{~L}^{-1} \mathrm{MA}$ for $120 \mathrm{~s}$ preconcentration. After each measurement the modified electrode was regenerated by successively cycling in the blank solution. The modified electrode was used to determine $1.0 \times 10^{-5} \mathrm{~mol} \mathrm{~L}^{-1} \mathrm{MA}$ for 6 times and the relative standard deviation (RSD) of the peak current was $4.3 \%$. Six modified electrodes were fabricated, and RSD was $3.7 \%$. This reveals the good reproducibility of the MWCNTs-AuNPs-DHP/GCE. 


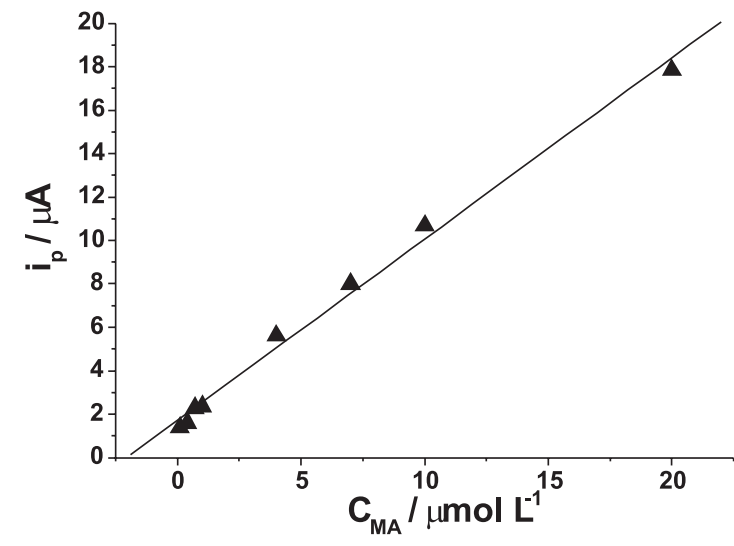

Figure 7. Linear plot of peak current $v s$ MA concentration. Other conditions as in Figure 4.

Under optimized experimental conditions, the interferences of some metal ions and organic compounds were evaluated. It was found that for $2 \times 10^{-6} \mathrm{~mol} \mathrm{~L}^{-1} \mathrm{MA}$, 100 folds of $\mathrm{NaCl}, \mathrm{KCl}, \mathrm{CuSO}_{4}, \mathrm{PbCl}_{2}, 10$ folds of vitamine $\mathrm{C}$, vitamine $\mathrm{B}_{1}$, L-Arginine $\mathrm{HCl}$, L-glutamic acid did not interfere with the determination of MA. However, 100 folds of $\mathrm{ZnSO}_{4}, \mathrm{MgSO}_{4}, \mathrm{Fe}_{2}\left(\mathrm{SO}_{4}\right)_{3}$ influenced the determination because they could form complexes with MA; $;^{8,9} 10$ folds of uric acid influenced the determination of MA due to their similar oxidation potential.

\section{Determination of MA in medicine capsule}

The proposed method was applied to the determination of MA in medicine capsule. The determination results were illustrated in Table 1. The recoveries were between $90 \%$ and $110 \%$. According to the calibration curve method, the content of MA in medicine capsule was calculated to be $90.7 \%$. To evaluate the accuracy of this method, UV-Vis absorption spectroscopy was used to determine the sample. MA caused three Soret absorption bands around 220, 284 and $346 \mathrm{~nm}$, respectively. The Soret absorption band located at $220 \mathrm{~nm}$ was chosen to determine the content of MA in the capsule because it was more sensitive, and the content was calculated to be $90.8 \%$ according to the calibration curve. It was consistent with the above result.

\section{Conclusions}

MWCNTs can be well dispersed in AuNPs colloid and a stable MWCNTs-AuNPs-DHP film coated electrode can be fabricated. The resulting electrode exhibits remarkable enhancement effect on the electrochemical oxidation of MA, and MA thus produces a sensitive anodic peak at about $0.6 \mathrm{~V}$ (vs. SCE). The peak results from 2e oxidation of MA,
Table 1. Determination results of MA in MA capsule

\begin{tabular}{ccccc}
\hline No. & $\begin{array}{c}\text { Sample/ } \\
\left(\mathrm{mol} \mathrm{L}^{-1}\right)\end{array}$ & $\begin{array}{c}\text { Added/ } \\
(\mathrm{mol} \mathrm{L})\end{array}$ & $\begin{array}{c}\text { Found/ } \\
\left(\mathrm{mol} \mathrm{L}^{-1}\right)\end{array}$ & $\begin{array}{c}\text { Recovery/ } \\
(\%)\end{array}$ \\
\hline 1 & $1.0 \times 10^{-6}$ & $2.0 \times 10^{-6}$ & $3.12 \times 10^{-6}$ & 106 \\
2 & $2.0 \times 10^{-6}$ & $3.0 \times 10^{-6}$ & $5.25 \times 10^{-6}$ & 108 \\
3 & $3.0 \times 10^{-6}$ & $4.0 \times 10^{-6}$ & $6.93 \times 10^{-6}$ & 98.3 \\
\hline
\end{tabular}

accompanied by two protons transfer. Under optimized conditions, the peak current is linear to MA concentration over a certain concentration range; hence the electrode can be used for the determination of MA.

\section{Acknowledgments}

The authors appreciate the support from the National Nature Science Foundation of China (Grant No. 20173040).

\section{References}

1. Dinç, E.; Yücesoy, C.; Onur, F.; J. Pharm. Biomed. 2002, 28, 1091.

2. García, S.; Sánchez-Pedreño, C.; Albero, I.; García, C.; Microchim. Acta 2001, 136, 67.

3. Sabry, S. M.; Anal. Chim. Acta 1998, 367, 41.

4. Albero, M. I.; Sanchez-Pedreño, C.; Garcia, M. S.; J. Pharm. Biomed. 1995, 13, 1113.

5. Ruiz, T. P.; Lozano, C. M.; Tomás, V.; Carpena, J.; Talanta 1998, 47, 537.

6. Rouini, M. R.; Asadipour, A.; Ardakani, Y. H.; Aghdasi, F.; J. Chromatogr., B 2004, 800, 189.

7. Aly, F. A.; Al-Tamimi, S. A.; Alwarthan, A. A.; Anal. Chim. Acta 2000, 416, 87.

8. Bojarowicz, H.; Kokot, Z.; Surdykowski, A.; J. Pharm. Biomed. 1996, 15, 339.

9. Topacli, A.; Ide, S.; J. Pharm. Biomed. 1999, 21, 975.

10. Liu, L.; Song, J.; Anal. Biochem. 2006, 354, 22.

11. Santini, A. O.; Pezza, H. R.; Pezza, L.; Sens. Actuators, B 2007, $128,117$.

12. Iijima, S.; Nature 1991, 354, 56.

13. Davis, J. J.; Richard, J. C.; Allen, O.; Hill, H.; J. Electroanal. Chem. 1997, 440, 279.

14. Luo, H.; Shi, Z.; Li, N.; Gu, Z.; Zhang, Q.; Anal. Chem. 2001, 73,915 .

15. Britto, P. J.; Santhanam, K. S. V.; Alonso, V.; Rubio, A.; Ajayan, P. M.; Bioelectrochem. Bioenerg. 1996, 41, 121.

16. Musamech, M.; Wang, J.; Merkoci, A.; Lin, Y. H.; Electrochem. Commun. 2002, 4, 743.

17. Wang, J.; Musameh, M.; Anal. Chim. Acta 2004, 511, 33. 
18. Yan, X. X.; Pang, D. W.; Lu, Z. X.; Lu, J. Q.; Tong, H.; J. Electroanal. Chem. 2004, 569, 47.

19. Xu, J.; Wang, Y. P.; Xian, Y. Z.; Jin, L. T.; Tanaka, K.; Talanta 2003, 60, 1123.

20. Wu, K. B.; Hu, S. S.; Bai, W.; Anal. Chim. Acta 2003, 489, 215.

21. Wu, K. B.; Sun, Y. Y.; Hu, S. S.; Sens. Actuators, B 2003, 96 , 658.

22. Wang, J.; Musameh, M.; Lin, Y.; J. Am. Chem. Soc. 2003, 125, 2408.

23. Zhang, M.; Smith, A.; Gorski, W.; Anal. Chem. 2004, 76, 5045.
24. Wu, Y. H.; Hu, S. S.; Colloids Surf., B 2005, 41, 299.

25. Zhao, J.; Yu, J. J.; Wang, F.; Hu, S. S.; Microchim. Acta 2007, 156, 277.

26. Laviron, E.; J. Electroanal. Chem. 1974, 52, 355.

27. Jin, G. P.; Lin, X. Q.; Electrochim. Acta 2005, 50, 3556.

28. Chen, G. N.; Zhao, Z. F.; Wang, X. L.; Duan, J. P.; Chen, H. Q.; Anal. Chim. Acta 2002, 452, 245.

Received: June 6, 2007 Web Release Date: March 31, 2008 